- Điều trị trước khi đến khám: Nhóm chưa điều trị chiếm tỷ lệ cao nhất $(51,02 \%)$ kế đến là nhóm điều trị không chuyên khoa da liểu $(24,49)$, thấp nhất là nhóm điều tri khoán $(10,2 \%)$.

- Thương tổn cơ bản: Hồng ban gặp ở hầu hết các bệnh nhân $(93,88 \%)$, kế đến là mụn nước, bóng nước (79,59\%), sẹo gặp rất ít (6,12\%).

- Vị trí thương tổn: Nhóm đầu mặt cổ và liên sườn ngực tay chiếm tỷ lệ cao nhất $(32,65 \%)$, thấp nhất là chi dưới (18,37\%).

\section{Kết quả điêuu trị}

- Trong quá trình điều trị, 100\% bệnh nhân hài lòng với kết quả điều trị.

- Kết quả điều trị: Sau 7 ngày, có 60,47\% bênh đáp ứng tốt, $25,58 \%$ bệnh đáp ứng trung bình, $13,95 \%$ kém. Sau 14 ngày, có $86,49 \%$ bệnh đáp ứng tốt, 10,81\% bệnh đáp ứng trung bình, 10,81\% kém. Sau 21 ngày, có $89,19 \%$ bệnh đáp ứng tốt, $8,11 \%$ bệnh đáp ứng trung bình, 10,81\% bệnh kém.

- Không ghi nhận tác dụng phụ nào.

TÀI LIỆ THAM KHẢO

1. Nguyễn Lan Anh, Đặng Văn Em (2015),
"Nghiên cứu một số đặc điểm dịch tễ và lâm sàng của bênh zona tại bệnh viện Trung ương Quân đội 108", Y hoc thực hành, 3 (953), tr.38-42.

2. Bộ Y tế (2015), "Bếnh zona", Hướng dẫn chẩn đoán và điêu tri các bểnh $\mathrm{Da}$ liễu, tr.67-71.

3. Tô Thị Thúy Hằng, võ Hồng Khôi (2018), "Đặc điểm đau trong bệnh zona theo thang điêm trực quan tương ứng (VAS)", Tạp chí y học Việt Nam, $1 \& 2$ (467), tr.100-103.

4. Nguyên Thị Thu Hoài (2011), "Mô tả một vài đặc điểm dị̣ch tê̂, lâm sàng bệnh zona điều trị tại khoa da liểu bênh viên đa khoa trung ương Thái nguyên và bệnh viện 103", Khoa học \& công nghệ, $112(12) / 2$, tr. $237-243$.

5. Đố Văn Khoát (1998), Nghiên cứu tình hình bệnh zona tai Viện Da liễu Việt Nam từ 19941998, Luân vằn thạc sỹ y học.

6. Kosuke Kawai , Barbara P Yawn, Peter Wollan et al (2016), "Increasing Incidence of Herpes Zoster Over a 60-year Period From a Population-based Study", Clin Infect Dis, 63 (2), pp.221-226.

7. Robert W. Johnson, Marie-José AlvarezPasquin, Marc Bijl et al (2015), "Herpes zoster epidemiology, management, and disease and economic burden in Europe: a multidisciplinary perspective", Ther Adv Vaccines, 3 (4), pp.109-120.

\title{
HIỄU QUẢ ĐIỀU TRI ĐAU VÙNG CỔ GÁY DO THOÁI HÓA CộT SỐNG BĂNG BÀI THUỐC TAM TÝ THANG KẾT HỢP ĐIỆN CHÂM HUYÊTT GIÁP TÍCH CộT SỐNG Cổ
}

\section{TÓM TẮT}

Mục tiêu: Đánh giá hiệu quả điều trị đau vùng cổ gáy do thoái hóa cột sốngbằng bài thuốc Tam tý thang kết hợp điện châm huyệt giáp tích cột sống cố. Đối tượng và̀ phướng pháp: 60 bểnh nhân tuổi từ 30 75 được chẩn đoán đau vùng cổ gáy do thoái hóa cột sống, không phân biêt giới tính, nghề nghiêp, tình nguyện tham gia nghiên cứu. Nhóm nghiên cứu điêu trị bẳng uống bài thuốc Tam tý thang kết hợp điện châm huyệt giáp tích cột sống cổ, nhóm đối chứng điều trị bằng điện châm huyệt giáp tích cột sống cổ đơn thuần. So sánh kết quả sau 14 ngày điều trị. Kết quả: bài thuốc Tam tý thang kết hợp điện châm huyệt giáp tích cột sống cổ hiệu quả trong điều trị đau vùng cổ gáy do thoái hóa cột sông, 96,7\% đạt hiệu quả tốt. Biên độ hoạt động cột sống cổ, mức độ đau và chức năng sinh hoạt hàng ngày NPQ cải thiện tốt hơn có ý

${ }^{1}$ Viện Y họ cổ truyền Quân đội,

ªểnh viện Châm cứu Trung ướng

Chịu trách nhiệm chính: Nguyễn Vinh Quốc

Email: quocnguyenvinh@gmail.com

Ngày nhân bài: 25/4/2021

Ngày phản biên khoa hoc: 25/5/2021

Ngày duyệt bài: 20/6/2021
Nguyễn Vinh Quốc ${ }^{1}$, Nguyễn Đức Minh ${ }^{2}$ nghĩa so với trước điều trị và tốt hơn so với nhóm đối chứng. Kết luận: bài thuốc Tam tý thang kết hợp điện châm huyệt giáp tích cột sống cổ hiệu quả tốt trong điêu trị đau vùng cổ gáy do thoái hóa cột sống.

Tư khóa: Đau vùng cổ gáy, huyệt giáp tích cột sống cổ, điện châm.

\section{SUMMARY}

THE EFFECT OF "TAM TY THANG" COMBINED WITH ELECTRO-ACUPUNCTUREAT CERVICAL JIAJI POINT ON TREATING NECK PAIN WITH CERVICAL SPONDYLOSIS

Objective: To evaluate effect of "Tam ty thang" withelectro-acupuncture at cerviacal Jiaji pointon treament of neck pain with cervical spondylosis. Subjects and methods: 60 volunteered patients aged from 30 to 75 diagnosed with neck pain with cervical spondylosis, regardless of gender or occupation, were participated in the study. Researchers combined using "Tam ty thang"withelectro-acupuncture at cerviacal Jiaji point, while the control group was treated by electroacupuncture at cerviacal Jiaji point. Comparing the results after 14 days treatment. Result: The spondylosis of neck pain with cervical spinetreating 
method by using the combination of "Tam ty thang" with electro-acupuncture at cerviacal Jiaji pointworked efficiency, $96.7 \%$ rate of good results. The amplitude of activity of the cervical spine, pain level and the NPQ score improved better than before treatment and better than control group, difference is statistically significant. Conclusion: The treating method using "Tam ty thang" combined withelectro-acupuncture at cerviacal Jiaji pointshow pleasing outcome during treatment for the neck pain with cervical spondylosis.

Keyword: Neck pain, cerviacal Jiaji point,electroacupuncture.

\section{I. ĐẶT VẤN ĐỀ}

Đau vùng cổ gáy (hội chứng cổ vai cánh tay, hội chứng vai tay) do thoái hóa cột sống (THCS) là bệnh lý thường gặp với biểu hiện lâm sàng cơ bản là đau vùng cổ vai lan xuống cánh tay, cẳng tay kèm rối loạn cảm giác, vận động tại vùng chi phối của rễ dầy thần kinh cột sống cổ [1], [2]. Bệnh ít nguy hiểm tới tính mạng nhưng gây ảnh hưởng nhiều tới sức khỏe, suy giảm khả năng học tập, lao động cũng như ảnh hưởng không tốt tới chất lượng cuộc sống của người bệnh[1], [3], [4]... Do vậy điều trị và điều trị dự phòng bệnh lý này là yêu cầu cấp thiết đối nhằm nhanh chóng giúp người bệnh giải phóng khỏi tình trang đau, cải thiện chức năng vận động cột sổng, khôi phục khả năng lao động và cải thiện chất lượng sinh hoạt hàng ngày.

Y hoc cổ truyền (YHCT) quy nạp bênh lý đau vùng cổ gáy do THCS vào phạm trù Chứng tý.Có nhiều phương pháp điều trị bệnh lý này được áp dung mang lai hiệu quả tốt trong đó phương pháp điều trị dùng thuốc YHCT kết hợp can thiệp không dùng thuốc [3], [4], [5]...

Tam tý thang là bài thuốc cổ phương YHCT có tác dụng ích can thận, bổ khí huyết, trừ phong thấp, chỉ thống tý, được nhiều thầy thuốc YHCT lựa chọn để điều trị các bệnh lý xương khớp trong đó có bệnh lý THCS cổ [5],[6]... Các nghiên cứu khoa học cho thây, thông qua tác động tại chỗ, phản ứng tiết đoạn và phản ứng toàn thân, điện châm nói chung và điện châm huyệt giáp tích cột sống cổ có tác dụng kích thích cơ thể giảm hàm lượng Cathecholamin, tăng hàm lượng Achetylcholin và làm sản sinh Endorphin nội sinh, từ đó đạt hiệu quả giảm đau [3],[4],[5],[7], [8]. Do vậy nghiên cứu được thực hiện nhằm mục tiêu đánh giá hiệu quả điểu trị đau vùng cổ gáy do THCS bằng bài thuốc Tam tý thang kết hợp điện châmhuyệt giáp tích cột sông cổ.

\section{II. ĐỐI TƯỢNG VÀ PHƯƠNG PHÁP NGHIÊN CỨU \\ 2.1. Chất liêu}

- Bài thuốc "Tam tý thang" (Phụ nhân lương phương)[6]: Độc hoạt 10, Tần giao 12g, Tế tân 04g, Bạch linh 12g, Bạch thược 12g, Sinh địa $12 \mathrm{~g}$, Đẳng sâm $12 \mathrm{~g}$, Ngưu tất $12 \mathrm{~g}$, Đương quy $12 \mathrm{~g}$, Xuyên khung $12 \mathrm{~g}$, Tục đoạn $12 \mathrm{~g}$, Đỗ trọng $12 \mathrm{~g}$, Phòng phong $12 \mathrm{~g}$, Hoàng kỳ $12 \mathrm{~g}$, Quế chi 05g, can khương 04g, Cam thảo $06 \mathrm{~g}$.

Thuốc được chiết sắc bằng máy và đóng túi tự động, một thang đóng vào 2 túi, mỗi túi $100 \mathrm{ml}$.

- Máy điện châm KWD - TN09 - T06; thước đo thang điểm VAS (Visual analogue scale); thước đo tầm vận động cột sống cổ.

- Kim châm cứu 1 lần các cỡ phù hợp với yêu cầu kỹ thuật, pince, bông, cồn $70^{\circ}$.

\section{2. Đối tượng nghiên cứu}

60 bệnh nhẩn (BN) tuổi $30-75$, không phân biệt giới tính, nghề nghiệp, tình nguyện tham gia nghiên cứu được chẩn đoán đau vùng cổ gáy do THCS[1], [2]. Điều trị tại Bệnh viện Châm cứu Trung ương/Bộ Y tế từ tháng 08/2018- tháng 04/2019. Không đưa vào nghiên cứu những trường hợp ung thư, chấn thương, dị dạng cột sống, bệnh lý ngoài cột sống gây đau.

2.3. Phương pháp nghiên cứu. Thử nghiệm lâm sàng tiến cứu, so sánh kết quả trước và sau điều trị có đối chứng. Chọn mẫu có chủ đích theo phương pháp ghép cặp đảm bảo tương đồng về tuổi, giới tính, nghề nghiệp, thời gian mắc bệnh. Các $B N$ được chia thành 2 nhóm, mỗi nhóm $30 \mathrm{BN}$ :

- Nhóm đối chứng (NĐC): được điện châm 6 huyệt giáp tích vùng cổ, mỗi bên 3 huyệt, luân phiên 2 tổ hợp $(C 3, C 5, C 7)$ và $(C 2, C 4, C 6)$, châm tả mỗi ngày 1 lần $x 20$ phút/lần. Liệu trình điêu trị 14 ngày.

- Nhóm nghiên cứu (NNC): được điều trị như NĐC kết hợp uống nước sắc bài thuốc Tam tý thang ngày 2 túi chia 2 lần sáng chiều $x 14$ ngày.

Chỉ tiêu theo dõi và đánh giá:

- Lâm sàng: Đánh giá cải thiện mức độ đau theo thang điểm VAS (Visual Analog Scales), mức độ cải thiện tầm vận động cột sống cổ các tư thế cúi, nghiêng, xoay bằng thước đo nhân trắc học, mức độ cải thiện chức năng sinh hoạt hàng ngày theo thang điểm NPQ (Northwick Park Neck Pain Questionaire)[1].

- Đánh giá tác dụng không mong muốn của phương pháp (vựng châm, tụ máu, chảy máu, nhiễm khuẩn, mẩn ngứa, rối loạn tiêu hóa), biến đổi chỉ số mach, huyết áp sau điều trị.

Các chỉ tiêu theo dõi được đánh giá tại thời điểm trước điều trị $\left(T_{0}\right)$, sau 7 ngày điều trị $\left(T_{1}\right)$ vàkhi kết thúc liệu trình điều trị $\left(T_{2}\right)$.

- Đánh giá kết quả điều trị chung: so sánh điểm các chỉ tiêu theo dõi lâm sàng trước và sau điều trị, phân thành loại tốt (tổng số điểm sau 
điều trị giảm $>80 \%$ so với trước điều trị); Khá (tổng số điểm sau điều trị giảm $61-80 \%$ so với trước điều trị); Trung bình (tổng số điểm sau điều trị giảm 40-60\% so với trước điều trị); Kém (tổng số điểm sau điều trị giảm $<40 \%$ so với trước điều trị)[8].

2.4. Xử lý số liệu. Các số liệu được xử lý theo phương pháp thống kê y sinh học bằng phần mềm SPSS 16.0 for Windows. Các thuật toán được áp dụng: tính tỷ lệ phần trăm, tính sô trung bình, độ lệch chuẩn, so sánh số trung bình theo thuật toán T-Student.

\section{KẾT QUẢ NGHIÊN CỨU}

\subsection{Hiệu quả điêu trị}

Bảng i. Cải thiênn mức độ đau (VAS) sau điều tri (điêm; ${ }^{X} \pm S D$ )

\begin{tabular}{|c|c|c|c|}
\hline $\begin{array}{l}\text { Thời } \\
\text { điểm }\end{array}$ & $\begin{array}{l}\text { NNC(1) } \\
(n=30)\end{array}$ & $\begin{array}{l}\text { NĐC(2) } \\
(n=30)\end{array}$ & $\mathbf{p}_{1-2}$ \\
\hline $\mathrm{T}_{0}^{\text {(a) }}$ & $7,70 \pm 0,65$ & $7,43 \pm 0,72$ & $>0,05$ \\
\hline$T_{1}(\mathrm{~b})$ & $4,70 \pm 0,53$ & $4,97 \pm 0,76$ & $>0,05$ \\
\hline $\mathrm{T}_{2}(\mathrm{c})$ & $2,07 \pm 0,86$ & $2,60 \pm 1,00$ & $<0,05$ \\
\hline p & $\begin{array}{l}\text { pa-b; } p_{a-c} ; p_{b-} \\
c<0,05\end{array}$ & $\begin{array}{c}\mathrm{Pa-b}_{\mathrm{a}} ; \mathrm{p}_{\mathrm{a}-\mathrm{c} ;} ; \mathrm{p}_{\mathrm{b}-\mathrm{c}} \\
<0,05\end{array}$ & \\
\hline
\end{tabular}

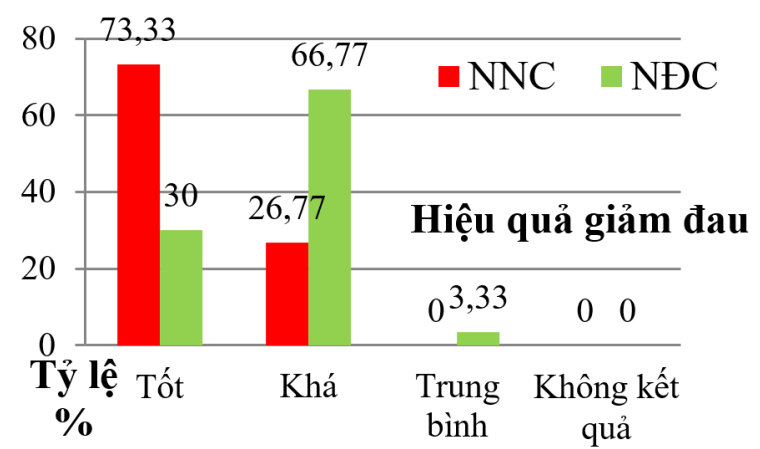

Biểu đồ 1. Hiệu quả giảm đau sau 14 ngày điều trị Mức độ đau theo thang điểm VAS có xu hướng giảm dần qua các thời điểm theo dõi ở cả 2 nhóm. Khác biệt tại thời điểm trước điều trị $\left(T_{0}\right)$ và sau điều trị $\left(T_{1} ; T_{2}\right)$ khi so sánh cùng nhóm có ý nghĩa thống kê $(p<0,05)$. Điểm giảm đau VAS trung bình sau 14 ngày điều trị ở NNC tốt hơn NĐC với $p<0,05$. Hiêu quả giảm đau sau kết thúc liệu trình điều trị đánh giá ở mức độ tốt ở NNC (73,33\%), cao hơn NĐC (30\%).

Bảng 2. Cải thiện tầm vận động cột sông cổ sau điều trị (độ; $X \pm S D)$

\begin{tabular}{|c|c|c|c|c|}
\hline Động tác & Thời điếm & $N_{N C}^{(1)}(n=30)$ & $N^{\prime} C^{(2)}(n=30)$ & p1-2 \\
\hline \multirow{4}{*}{ Cúi } & $\mathrm{T}_{0}{ }^{(\mathrm{a})}$ & $22,63 \pm 2,91$ & $23,80 \pm 2,91$ & $>0,05$ \\
\hline & $\mathrm{T}_{1}{ }^{(\mathrm{b})}$ & $29,30 \pm 3,60$ & $29,13 \pm 2,17$ & $>0,05$ \\
\hline & $\mathrm{T}_{2}{ }^{(\mathrm{c})}$ & $35,95 \pm 3,45$ & $33,93 \pm 2,47$ & $<0,05$ \\
\hline & $\mathrm{p}$ & & & \\
\hline \multirow{4}{*}{ Nghiêng } & $\mathrm{T}_{0}{ }^{(\mathrm{a})}$ & $24,87 \pm 3,40$ & $25,90 \pm 2,39$ & $>0,05$ \\
\hline & $\mathrm{T}_{1}$ (b) & $31,43 \pm 3,62$ & $31,10 \pm 2,57$ & $>0,05$ \\
\hline & $\mathrm{T}_{2}^{(\mathrm{c})}$ & $39,25 \pm 5,61$ & $36,70 \pm 3,77$ & $<0,05$ \\
\hline & $\mathrm{p}$ & $\mathrm{p}_{a-b} ; \mathrm{p}_{a-c} ; \mathrm{p}_{\mathrm{b}-\mathrm{c}}<0,05$ & $\mathrm{p}_{a-b} ; \mathrm{p}_{\mathrm{a}-\mathrm{c} ;} ; \mathrm{p}_{\mathrm{b}-\mathrm{c}}<0,05$ & \\
\hline \multirow{4}{*}{ Xoay } & $\mathrm{T}_{0}(\mathrm{a})$ & $32,37 \pm, 75$ & $34,87 \pm 4,59$ & $>0,05$ \\
\hline & $\mathrm{T}_{1}{ }^{(\mathrm{b})}$ & $41,30 \pm 5,51$ & $42,63 \pm 3,30$ & $>0,05$ \\
\hline & $\mathrm{T}_{2}(\mathrm{c})$ & $52,32 \pm 6,12$ & $48,97 \pm 3,58$ & $<0,05$ \\
\hline & $\mathrm{p}$ & pa-b; pa-c; pb-c $_{b-0,05}$ & $\mathrm{p}_{\mathrm{a}-\mathrm{b}} ; \mathrm{p}_{\mathrm{a}-\mathrm{c}} ; \mathrm{p}_{\mathrm{b}-\mathrm{c}}<0,05$ & \\
\hline
\end{tabular}

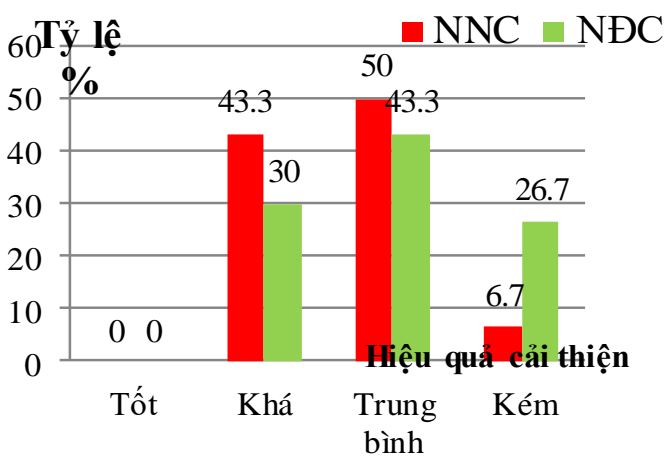

Biểu đồ 2. Hiệu quả cải thiện tầm vận động cột sông cổ sau 14 ngày điều trị
Tầm vận động cột sống cổ các động tác cúi, nghiêng, xoay đều cải thiện qua các thời điểm đánh giá, khác biệt tại thời điểm trước điều trị $\left(T_{0}\right)$ và sau điều trị $\left(T_{1} ; T_{2}\right)$ khi so sánh cùng nhóm có ý nghĩa thống kê $(p<0,05)$. Tầm vận động cột sống cổ các động tác sau 14 ngày điều trị ở NNC tốt hơn NĐC với $p<0,05$. Hiêuu quả cải thiện tầm vận động cột sống cổ sau 14 ngày điều trị đánh giá ở mức khá ở NNC (43,3\%), cao hơn NĐC (30\%).

Bảng 3. Cải thiện điểm NPQ sau điều trị (diếm; $X \pm S D$ )

\begin{tabular}{|c|c|c|c|}
\hline $\begin{array}{l}\text { Thời } \\
\text { điểm }\end{array}$ & $\begin{array}{r}\text { NNC(1) } \\
(n=30)\end{array}$ & $\begin{array}{c}N \oplus C^{(2)} \\
(n=30)\end{array}$ & $\mathbf{p}_{1-2}$ \\
\hline$T_{0}(\mathrm{a})$ & $20,07 \pm 2,74$ & $18,83 \pm 2,78$ & $>0,05$ \\
\hline
\end{tabular}




\begin{tabular}{|c|c|c|c|}
\hline $\mathrm{T}_{1}{ }^{(\mathrm{b})}$ & $12,73 \pm 1,74$ & $13,50 \pm 1,88$ & $>0,05$ \\
\hline $\mathrm{T}_{2}{ }^{(c)}$ & $3,43 \pm 1,16$ & $4,43 \pm 2,01$ & $<0,05$ \\
\hline $\mathrm{p}$ & $\begin{array}{c}\text { Pa-b; } \mathrm{Pa}_{a-c ;} ; \mathrm{P}_{\mathrm{b}-\mathrm{c}} \\
<0,05\end{array}$ & $\begin{array}{l}\text { Pa-b; } p_{a-c} ; p_{b-} \\
c<0,05\end{array}$ & \\
\hline $\begin{array}{c}\text { Mức } \\
\text { giảm } \\
\left(\mathrm{T}_{2}-\mathrm{T}_{0}\right)\end{array}$ & $\begin{array}{c}16,63 \pm \\
2,96\end{array}$ & $\begin{array}{c}14,40 \pm \\
2,92\end{array}$ & $<0$, \\
\hline
\end{tabular}

Chức năng sinh hoạt hàng ngày theo thang điểm NPQ cải thiện qua các thời điểm theo dõi ở cả 2 nhóm BN nghiên cứu, khác biệt trước $\left(T_{0}\right)$ và sau điều trị $\left(T_{1} ; T_{2}\right)$ khi so sánh cùng nhóm có ý nghĩa thống kê $(p<0,05)$. Điểm NPQ trung bình cũng như mức giảm điểm NPQ sau 14 ngày điều trị ở NNC tốt hơn NĐC với $p<0,05$.

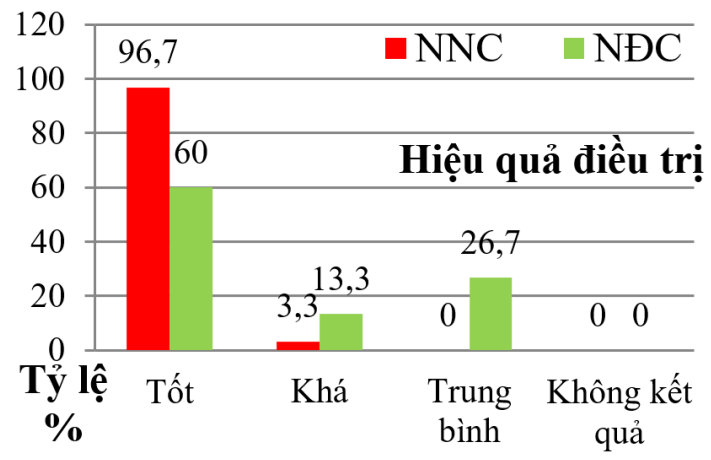

Biểu đồ 3. Kết quả điều trị chung

Sau điều trị, 96,7\% BN ở NNC đat kết quả tốt, cao hơn NĐC (60\%). Không có trường hợp nào không đáp ứng với điều trị.

3.2. Tác dụng không mong muốn của phương pháp. Trong quá trình điều trị, NNC xuất hiện 1 trường hợp rối loạn tiêu hóa (đau bụng, đại tiện phân nát), sau khi được xử trí thông thường đã ổn định và tiếp tục tham gia nghiên cứu. Không có trường hợp nào bị vựng châm, tụ máu, chảy máu, nhiễm khuẩn tai chỗ.

Bảng 5. Thay đổi tân số mạch, chỉ số huyết áp sau điều trị (X士 SD)

\begin{tabular}{|c|c|c|c|c|}
\hline & & & & \\
\hline Thời điểm & Chỉ tiêu & $\operatorname{NNC}^{(1)}(n=30)$ & $N \bigoplus C^{(2)}(n=30)$ & $\mathbf{p}_{1-2}$ \\
\hline$T_{0}(a)$ & \multirow{3}{*}{ Mạch (lần/phút) } & $75,1 \pm 7,1$ & $68,9 \pm 2,4$ & $>0,05$ \\
\hline $\mathrm{T}_{2}(\mathrm{c})$ & & $73,9 \pm 4,7$ & $68,8 \pm 2,3$ & $>0,05$ \\
\hline $\mathrm{Pa}-c$ & & $>0,05$ & $>0,05$ & \\
\hline $\mathrm{T}_{0}^{\text {(a) }}$ & \multirow{3}{*}{$\begin{array}{l}\text { Huyết áp tâm thu } \\
(\mathrm{mmHg})\end{array}$} & $123,8 \pm 19,4$ & $114,3 \pm 7,2$ & $>0,05$ \\
\hline$T_{2}(c)$ & & $114,3 \pm 7,2$ & $115,5 \pm 7,7$ & $>0,05$ \\
\hline$P_{a-c}$ & & $>0,05$ & $>0,05$ & \\
\hline$T_{0}$ (a) & \multirow{3}{*}{$\begin{array}{l}\text { Huyết áp tâm trương } \\
(\mathrm{mmHg})\end{array}$} & $76,2 \pm 10,8$ & $69,5 \pm 3,3$ & $>0,05$ \\
\hline $\mathrm{T}_{2}{ }^{(c)}$ & & $74,5 \pm 5,4$ & $69,4 \pm 2,1$ & $>0,05$ \\
\hline$P_{a-c}$ & & $>0,05$ & $>0,05$ & \\
\hline
\end{tabular}

Tần số mạch, chỉ số huyết áp trước và sau điều trị thay đối không có ý nghĩa thống kê $(p>0,05)$.

\section{BÀN LUẬN}

4.1. Cơ sở lựa chọn thực hiện nghiên cứu. Đau vùng cổ gáy do THCS được mô tả trong phạm trù chứng Tý, chứng "Cảnh kiên tí" của YHCT'2]. Đã có nhiều nghiên cứu mô tả và bàn luận về nguyên nhân, cơ chế bệnh sinh, phân thể điều trị chứng bệnh này. Đa số các nghiên cứu đều thống nhất cho rằng bệnh có liên quan mật thiết tới sự thịnh suy của thể chất, môi trường, hoàn cảnh sinh sống, điêuu kiện làm việc[3], [4]. Nguyên nhân và cơ chế bệnh sinh của đau vùng cổ gáy do THCSthể hàn thấp chủ yếu là do khí huyết, can tỳ thận hư tổn là bản; phong hàn thấp tàthừa hư xầm nhập, khí trệ huyết ứ là tiêu. Điều trị cần phải bố khí huyết, ích can thận để trị bản, đồng thời kết hợp với khứ phong, tán hàn, trừ thấp, hành khí, hoạt huyết để trị tiêu. Tuy nhiên cần căn cứ vào thời điểm cụ thể của bệnh mà cần biện rõ hoãn cấp để lựa chọn pháp điều trị phù hợp[2].Tam tý thang là bài thuốc có tác dụng bố can tỳ thận, bổ khí huyết để phù chính, trị vào bản chất của bệnh; vừa có tác dụng khu phong, tán hàn, trừ thấp để trị tiêu nên đáp ứng được đầy đủ về pháp điêu trị đã đề ra[6].

Để tăng cường hiệu quả điều trị, nhanh chóng trả lại khả năng lao động, sức khỏe cho người bệnh thì cần phối hợp nhiều phương pháp điêu trị, trong đó có những phương pháp không dùng thuốc. Các nghiên cứu hiện đại cho thây thông qua tác động tại chỗ, phản ứng tiết đoạn và phản ứng toàn thân, điện châm huyệt giáp tích cột sống cổ có tác dụng kích thích phản ứng cơ thể gây giảm hàm lượng Cathecholamin, tăng hàm lượng Achetylcholin và làm sản sinh Endorphin nội sinh, từ đó đạt hiệu quả giảm đau, cải thiện khả năng hoạt động khớp. Đã có nhiều nghiên cứu lựa chọn áp dụng điện châm điều trị các bệnh lý cột sống và thu được hiệu quả khá tốt[7], [8].Đây là cơ sở để chúng tôi lựa chọn thực hiện nghiên cứu này.

\subsection{Kết quả điêu trị}


*Cải thiện mức độ đau theo thang điểm VAS. Trong đau vùng cổ gáy do THCS, đau là triệu chứng chính khiến người bệnh phải tới khám và điêu trị tại cơ sở y tế[1]. VAS là thang điểm thông dụng để đánh giá mức độ đau được lựa chọn trong nhiều nghiên cứu cũng như nghiên cứu này. Kết quả cho thấy mức độ đau VAS ở cả 2 nhóm BN đêu được cải thiện sau điều trị, điểm VAS trung bình trước và sau điều trị khác biệt có ý nghĩa thống kê.VAS trung bình sau 14 ngày điều trị ở NNC tốt hơn có ý nghĩa so với NĐC chỉ dùng phương pháp điện châm đơn thuần. Hiệu quả giảm đau ở NNC sau kết thúc liệu trình điều trị đánh giá ở mức độ tốt cao hơn NĐC. Kết quả này chứng tỏ bài thuốc Tam tý thang kết hợp điện châm huyệt giáp tích cột sống cổ đã có hiệu quả giảm đau. Tam tý thang là bài thuốc có tác dụng khu phong, tán hàn, trừ thấp, hành khí hoạt huyết, giúp khí huyết trong kinh mạch được lưu thông, theo lý luận YHCT "thông tắc bất thống" do vậy có tác dụng giảm đau[5],[6]. Mặt khác kết hợp với các tác động tại chỗ, phản ứng tiết đoạn và phản ứng toàn thân của điện châm huyệt giáp tích cột sống cổ đãkích thích cơ thể sản sinh Endorphin nội sinh,qua đóđã giúp đạt hiệu quả giảm đau tốt và nhanh hơn điện châm đơn thuần[7], [8].

* Cải thiện biên độ hoạt động cột sống cổ. Cột sống cổ có tầm vận động rộng và linh hoạt, hạn chế vận động trong bệnh lýTHCS cổ chủ yếu nguyên nhân do tác nhân viêm gây phản xạ co rút hệ dây chằng, các cơ cạnh sống[1]. Sau 14 ngày điều trị, biên độ hoạt động cột sống cổ các động tác ở cả 2 nhóm BN đều tăng có ý nghĩa so với trước điều trị. Tầm vận động cột sống cổ các động tác ở NNC sau 14 ngày điều trị cải thiện tốt hơn có ý nghĩa so với NĐC, hiệu quả đánh giá ở mức khá ở NNC đat 43,3\%. Theo nhận định của chúng tôi, do tác dụng hành khí hoạt huyết, lý khí chỉ thống của bài thuốc Tam tý thangkết hợp cùng tác dụng giảm đau, giãn cơ của điện châm đã giúp cho biên độ hoạt động cột sống cổ ở các tư thế được cải thiện đáng kể sau điêu trị.

* Cải thiện chức năng sinh hoạt hàng ngàytheo thang điểm NPQ. Bộ câu hỏi NPQ thường được sử dụng để đánh giá mức độ đau và ảnh hưởing của đau vùng cổ gáy do THCS lên các chức năng sinh hoạt hàng ngày của người bệnh[1]. Đây là phương pháp đơn giản, dể sử dụng và là công cụ đo đạc khách quan được nhiều nghiên cứu áp dụng[3], [4]... Sau điều trị, chức năng sinh hoạt hàng ngày theo thang điểm NPQ ở cả 2 nhóm BN nghiên cứu đều cải thiện có ý nghĩa so với trước điều trị. Mức giảm điểm NPQ ở các BN NNC thời điểm trước và sau 14 ngày điều trị đạt 16,63 $\pm 2,96$ (điểm), tốt hơn có ý nghĩa so với NĐC. Như vậy, bài thuốc Tam tý thang kêt hợp điên châm huyệt giáp tích cột sống cổđã góp phần nâng cao chất lượng sinh hoạt và hiệu suất lao động cho người bệnh. Đây cũng là nhận định của nhiều tác giả - Kết hợpthuốc YHCT với điện châmđạt được hiệu quả tốt trong điều trị các chứng đau mạn tính[3], [4], [5], [8].

*Hiệu quả điêu trị chung và tác dụng không mong muốn của phương pháp. Từ kết quả thay đổi điểm VAS, tầm vận động cột sống cổ, điểm NPQ trước và sau điều trị ở 2 nhóm BN nghiên cứu, chúng tôi nhận thấy đều có đáp ứng điều trị ở các mức độ khác nhau, tỷ lệ BN ở NNC sau 14 ngày điều trị đạt kết quả tốt $96,7 \%$, cao hơn NDC (60\%). Như vậy, bài thuốc Tam tý thang kết hợp điện châm huyệt giáp tích cột sống cổ có tác dụng tốt đối với các BN đau vùng cố gáy do THCS, kết quả này cũng phù hợp với lý luận YHCT về cơ chế tác dụng của bài thuốc nghiên cứu cũng như phương pháp điện châm [6], [7]. Trong quá trình thực hiện kỹ thuật chúng tôi không gặp tai biến nào, phương pháp không ảnh hưởng tới tần số mạch, chỉ số huyết áp trên cả 2 nhóm BN nghiên cứu. Kết quả này cho thấy trình độ và năng lực của kỹ thuật viên Bệnh viện Châm cứu Trung ươngkhi thực hiện các dịch vụ kỹ thuật chuyên ngành YHCT.

\section{KẾT LUÂ̂N}

Bài thuốc Tam tý thang kết hợp điện châm huyệt giáp tích cột sống cổcó hiệu quả tốt trong điều trị bệnh nhân đau vùng cổ gáy do thoái hóa cột sống. Tỷ lệ kết quả tốt sau 14 ngày điêu trị chiếm 96,7\%. Điểm VAS trung bình, điểm cải thiện chức năng sinh hoạt hàng ngày và biên độ hoạt động cột sống cổ sau điều trị đều được cải thiện có ý nghĩa so với thời điểm trước điều trị và tốt hơn so với nhóm nghiên cứu dùng điện châm đơn thuần.

\section{TÀI LIÊU THAM KHẢO}

1. Nguyễn Văn Thông (2011). Bệnh lý cột sống cổ, NXB Thanh niên, Hà Nôi.

2. Bộ Y tế (2020). Hội chứng cổ vai cánh tay. "Hiướng dẫn chẩn đoán và điêu trị bệnh theo y học cổ truyên, kết hợp y học cổ truyển với y học hiệ̂n đai". Ban hành kèm theo Quyêt định số $5013 / \mathrm{Q}$ ĐBÝT ngày 01/12/2020 của Bộ trưởng Bộ $Y$ tế, tập I, NXB Y học, Hà Nội, 37-43.

3. Lê Thị Diệu Hằng, Lại Thanh Hiên (2014), Đánh giá tác dụng điêu trị thoái hóa cột sống cồ bằng mãng điện châm kết hợp bài thuốc quyên tý thang. Tạp chí nghiên cứu Y $Y$ dược học cổ truyền 
Việt Nam, 40, 54-60.

4. Nguyến Tuyết Trang, Đào Thị Phương (2016). Hiêu quả của phương pháp điển châm và cấy chì catgut trong điêu trị đau vai gáy do thoái hóa cột sống cổ. Tap chí nghiên cứu Y hoc, 103(5), 17-23.

5. 黄曼丽, 黄惠萍, 罗桂欢 và cộng sự (2019). 三㢞汤 联合内热针 及针刀改善 神经根型颈 椎病患者根性疼痛及功能康复 的临床研究. 中国医学 创新, 16(2), 74-77.
6. Trân Quốc Bảo (2017). Các bài thuốc thường dùng trong $Y$ học cổ truyền và ứng dụng lâm sàng, NXB Quân đội nhân dân, Hà Nôii.

7. Bộ mốn Y học cổ truyên - Trường đại học $Y$ Hà Nô̂i (2005). Châm cứu, NXB Y hoc, Hà Nô̂i.

8. 王小丽, 张芙蓉, 吴松 và công sư (2016) 电针颈夹脊穴配合理筋手法治疗椎动脉型颈椎病临 床研究. 湖北中医药大学学报, 5, 87-89.

\title{
KHẢO SÁT MộT Số ĐĂC ĐIỂM LÂM SÀNG, CÂN LÂM SÀNG, TỔN THƯO'NG ĐộNG MACH VÀNH Ở BÊNH NHÂN HộI CHỨNG VÀNH CẤP ĐƯợC CAN THIỆP STENT CHỖ CHIA NHÁNH Độ̉NG MẠCH VÀNH
}

\author{
Lê Thanh Bình ${ }^{1,2}$, Phạm Mạnh Hùng ${ }^{2}$, Nguyễn Oanh Oanh ${ }^{1}$
}

\section{TÓM TẮT}

Mục tiêu: Khảo sát một số đặc điểm lâm sàng, cận lầm sàng, đặc điểm tổn thương động mạch vành ở bênh nhân hội chứng đônng mach vành cấp được can thiệp đặt stent chố chia nhánh động mạch vành. Phương pháp nghiên cứu: Nghiên cứu mô tả cắt ngang từ 5/2014 đến 12/2017. Đối tượng nghiên cứu là bệnh ñhân hội chứng vành cấp được can thiệp đặt stent chố chia nhánh động mạch vành tại Viện Tim mach - Bênh viện Bạch Mai và Bệnh viện Đại học Y Hà Nội. Kết quả: Qua nghiên cứu 141 bệnh nhân hội chứng động mạch vành cấp được can thiệp stent chỗ chia nhánh động mạch vành,tuổi trung bìnhcủa nhóm bệnh nhân nghiên cứu là $66,11 \pm 9,42$, tỷ lệ nam/nữ là 2,71/1. Một số yếu tố nguy cơ tim mạch bao gồm tăng huyết áp, đái tháo đường, hút thuốc lá lần lượt là $78,72 \%$ - 29,79\% và 24,11 \%. Tỷ lê nhồi máu cơ tim có ST chênh lên, nhồi máu cơ tim STं không chênh và đau thắt ngực không ổn định lần lượt là 27,66 \% $7,8 \%$ và $64,54 \%$. Hình ảnh điện tâm đồ có biểu hiện ST chênh lên là $27,66 \%$ và không thây biến đổi hình ảnh điện tâm đồ gặp 37,59 \%.Phẩn số tống máu thất trái $(\mathrm{EF})$ trung bình là $57,5 \pm 13,5 \%$ với tỷ lê bênh nhân có $E F \geq 40 \%$ chiếm 89,21\%. Hệ động mạch ưu năng phải chiếm đa số với tỷ lệ là $94,33 \%$. Tổn thương chỉ trên 1 nhánh động mạch vành chiếm tỷ lệ $65,96 \%$ và tổn thương nhiều nhánh đông mach vành gặp 34,04\%. Vị trí tốn thương chố chia nhánh động mạch vành găp nhiều nhất là ở động mạch liên thất trước với tỷ lệ gặp là $89,36 \%$ và vị trí tổn thương chố chia nhánh của động mạch thủ phạm ở động mạch liên thất trước là $79,43 \%$. Trên tổn thương động mạch vành thủ phạm, tổn thương phức tạp type $B 2$ và type $C$ theo phân loại của ACC/AHA chiếm đa sốvới tỳ lệ 96,45\%. Theo phân loại tổn thương chỗ chia nhánh

\section{${ }^{1}$ Học viện Quân Y}

2Viên Tim mach, Bênh viện Bach Mai

Chịu trách nhiệm chính: Lê Thanh Bình;

Email: lethanhbinhdr@gmail.com

Ngày nhận bài: 7/5/2021

Ngày phản biên khoa học: 26/5/2021

Ngày duyệt bài: 25/6/2021
Medina, có $48,23 \%$ tổn thương Medina 1.1 .1 , có $30,50 \%$ tổn thương Medina 1.1 .0 , có $4,26 \%$ tổn thương Medina 1.0.1, có 7,09\% tôn thương Medina 0.1 .1 , còn tổn thương Medina 1.0.0, Medina 0.1 .0 và Medina 0.0 .1 có tỷ lệ lần lượt là $4,26 \%-5,67 \%$ và $0 \%$. Tổn thương hep thực sự (bao gồm Medina 1.1.1, Medina 1.0 .1 và Medina 0.1 .1 ) là $59,57 \%$. Góc chia nhánha $<70^{\circ}$ chiếm tỷ lê $79,43 \%$. Điểm Syntax trung bình là $18 \pm 6,3$ với $80,85 \%$ các trường hợp có điểm Syntax < 23 điểm. Kết luận: bệnh gặp nhiều hơn ở nam giới, lớn tuổi, yếu tố nguy cơ tim mạch hay gặp nhất là tăng huyết áp. Tổn thương động mạch vành chố chia nhánh thường gặp nhất ở động mạch liên thất trước với tổn thương phức tạp theo phân loại Medina 1.1.1, Medina 1.1.0 và Medina 0.1.1 là hay gặp nhất. Góc chia nhánha $<70^{\circ}$ gặp phổ biến.

\section{SUMMARY \\ INVESTIGATION THE CLINICAL, LABORATORY, AND LESION CHARACTERISTICS IN PATIENTS WITH ACUTE CORONARY SYNDROME AND BIFURCATION LESSIO STENTING}

Objectives: To evaluate the clinical, laboratory, and lesion characteristics in patients with acute coronary syndrome (ACS) and bifurcation lesions stenting. Method: Observational study. This case series included 141 ACS patientswith bifurcation lesion underwent percutaneous coronary intervention at Vietnam National Heart Institute and Hanoi Medical University Hospital from May, 2014 to Dec, 2017.Results: The mean age of patients was $66,11 \pm$ 9,42 years; male/female ratio was $2.71 / 1$. Hypertension was present in $78.72 \%$ of the patients, diabetes and smoking were present in $29.79 \%$ and $24.11 \%$ of the patients, respectively. $27.66 \%$ and $7.8 \%$ of the patients had a ST elevation myocardial infaction (STEMI) and Non-STEMI, respectively. Unstable angina was present in $64.54 \%$ of the patients. Electrocardiogram (ECG) was normal in $37.59 \%$ of the patients and ST segment elevation occured in $27.66 \%$ of cases. The mean left ventricular ejection fraction (LVEF) was $57.5 \pm 13.5$ (\%) and $89.21 \%$ of patients with LVEF $\geq 40 \%$. 